\title{
ANTIOXIDANT ACTIVITIES OF Elaeis guineensis LEAVES
}

\section{ANG CHUN HUI*; CHENG SIT FOON* and CHUAH CHENG HOCK*}

\begin{abstract}
Fresh leaves from Elaeis guineensis fronds were subjected to ultrasonic-assisted methanol extraction. The crude methanolic extract $(\mathrm{MeOH})$ was then fractionated by repeated extractions, sequentially with solvents of different polarity into n-hexane (HEX), ethyl acetate (EA), water (WATER) and insoluble residue (INSOL) fractions. The antioxidant activity of the crude extract and its fractions was evaluated by in vitro 2,2-diphenyl-1-picrylhydrazyl (DPPH) radical-scavenging activity, lipid peroxidation (LPO) inhibition and beta-carotene bleaching assays. Total phenolic contents (TPC) in the fractions were determined with Folin-Ciocalteu reagent. The results indicated that the INSOL fraction showed the highest activity in $D P P H$ radical-scavenging activity assay and beta-carotene bleaching assay, while EA fraction exhibited highest activity through LPO inhibition. DPPH radical-scavenging activity of the fractions was negatively correlated (correlation coefficients $=-0.896,-0.943$ respectively, $P<0.050$ ) with the TPC based on Pearson Product Moment Correlation and Spearman Rank Order Correlation. The findings of present study suggests that oil palm leaves have high potential to be utilised as natural source of antioxidants in palm oil producing countries such as Indonesia, Malaysia and Thailand, where oil palm leaves are abundantly available.
\end{abstract}

Keywords: oil palm leaves, antioxidants, DPPH, LPO, TPC.

Date received: 21 June 2016; Sent for revision: 13 July 2016; Received in final form: 14 June 2017; Accepted: 13 July 2017.

\section{INTRODUCTION}

The oil palms (Elaeis) consist of two species of the family Arecaceae. They are commonly used in commercial agriculture in the production of palm oil. The African oil palm Elaeis guineensis is native to West Africa, while the American oil palm Elaeis oleifera is native to tropical Central America and South America. Elaeis guineensis is widely cultivated in Malaysia for its oil producing fruits (Maclellan, 1983). Mature oil palm are single-stemmed, and grow to $20 \mathrm{~m}$ tall. The leaves are pinnate, and reach 3-5 m long. A young oil palm produces about 30 leaves in a year. Matured oil palm over 10 years produce about 20 leaves in a year. The flowers are

\footnotetext{
* Unit of Research on Lipids (URL),

Department of Chemistry,

Faculty of Science,

Universiti Malaya,

50603 Lembah Pantai, Kuala Lumpur, Malaysia.

E-mail: sfcheng@um.edu.my
}

produced in dense clusters; each individual flower is small, consist three sepals and three petals. The palm fruit is reddish, about the size of a large plum and grows in large bunches. Each fruit is made up of oily, fleshy outer layer (the mesocarp), with a single seed (the kernel), also rich in kernel oil. The palm fruit takes five to six months to mature after pollination.

Palm oil is extracted from both the mesocarp of the fruit and the kernel. They are used for both food and non-food applications. Its increasing use in the commercial food industry is due to its economical pricing and the high oxidative stability of the refined products.

In Malaysia, the oil palm cultivation area reached 5.47 million hectares as reported up to December 2016; produced 24.91 million tonnes of crude palm oil in the year to fulfil worldwide food and non-food demands (MPOB, 2017a). Total export of palm oil was 16.05 million tonnes in 2016, worth RM 43369 million. Besides, there were also exports 
of other oil palm products such as palm kernel oil, palm kernel cake, oleochemicals, finished products, biodiesel and others, sum up to a total of 7.24 million tonnes, RM 21219 million (MPOB, 2017b). The oil palm biomasses produced as by-products in the form of oil palm trunk, fronds and empty fruit bunch are about 80 million tonnes (dry basis). The oil palm fronds are collected during pruning and replanting activities with average generation rate of 9.8 and $14.9 \mathrm{t}$ (dry mass) per hectare plantation area per year, respectively. Out of that 80 million tonnes dry mass, a tremendous amount of about 45 million $\mathrm{t}$ comes from the fronds (Ibrahim et al., 2012). Beside the production of edible oil from its fruits, some studies have been done on the beneficial effects of extracts derived from various parts of Elaeis guineensis. Neo et al. (2010) reported that the presence of phenolics from the by-products of palm oil milling and refining processes, that is from the fruits of oil palm. Tan et al. (2001) disclosed the presence of phenolic compounds in palm oil that is derived from oil palm fruit mesocarp and kernel. The phenolic compounds include gallic, chlorogenic, protocatechuic, gentisic, coumaric, ferulic and caffeic acids, as well as catechins, hesperidine, narirutin and 4-hydroxybenzoate. Besides, Lau et al. (2007) recovered water-soluble compounds in fresh palm-pressed fibre by supercritical carbon dioxide extraction and 12 compounds were identified from the extract. Some researchers also discovered oil palm leaves have potential health benefits.

Abeywardena et al. (2002) disclosed a polyphenol-enriched extract derived from Elaeis guineensis leaf. They reported that the said extract can be used to promote vascular relaxation via endothelium-dependent mechanisms. Mohamed et al. (2009) reported a method for preparing herbal extract from leaves of a plant of Arecaceae family (Elaeis guineensis, Elaeis oleifera, Phoenix dactylifera and Cocos nucifera) using polar solvent. The extract is reported to be incorporated into daily diet for improving cardiovascular system. Later, Mohamed et al. (2014) reported that oil palm leaf has $8 \%$ higher total phenols content than green tea extract and contains epigallocatechin, catechin, epicatechin and epigallocatechin gallate. She reviewed the health benefits of oil palm leaf extract on breast cancer, diabetes, hypertension, inflammation, oxidative stress, neurodegeneration, cognitive functions, dyslipidemia, cardiovascular, liver, kidney and neuroprotective properties. Balasundram et al. (2003) disclosed a phenolic-rich fraction isolated from oil palm fruits. This extract exhibits bioactive properties, in particular antioxidant effects. Kinnoudo (2007) disclosed extracts of Elaeis guineensis leaves that possess anti-malarial properties. Elaeis guineensis leaves are also reported to be a potent source of antioxidants ( $\mathrm{Ng}$ and Choo, 2010). Sun et al. (2001) discovered a new method of quantitative determination of hydroxycinnamic acids in oil palm leaf fibre. The analysis on other compounds was not included in the work done. Phang et al. (2009) characterised a composition of oil palm leaf extract comprises (-)-catechin gallate, ferulic acid and phenolic acids such as gallic acid and protocatechuic acid. A method of producing the said extract was claimed. Jaffri et al. (2011) reported the effects of catechin-rich oil palm leaf extract on normal and hypertensive rats' kidney and liver.

Antioxidants are recognised for their potent uses in improving health by lowering the risk for cancers, hypertension and heart disease via their ability of scavenging free radicals, prevent oxidation of body cells. These antioxidants can be consumed directly as they present in food or in the form of supplements. They can also be employed in food industry as food additives to prevent oxidation and degradation of food during processing and storage. Natural antioxidants from plant are attracting great interest from researchers worldwide due to some human health studies and scientific research about the safety of synthetic antioxidants in food (such as butylated hydroxytoluene, butylated hydroxyanisole and tertiary butyl hydroquinone) (Branen, 1975). The natural occurring antioxidant is focused more on edible plants, especially tea, fruits, vegetables, spices and herbs. They are an excellent source of phenolic compounds (secondary plant metabolites) such as flavonoids, phenolic acids and alcohols, stilbenes, tocopherols, tocotrienols, ascorbic acid and carotenoids which have been reported to show good antioxidant activity (Das and Pereira, 1990; Foti et al., 1996; Santana-Méridas et al., 2014; Tomas-Barberan et al., 2000).

The objectives of this study were to determine total phenolic contents (TPC) and evaluate antioxidant activity of oil palm leaves methanolic extract and its fractions by in vitro 2,2-diphenyl-1picrylhydrazyl (DPPH) radical-scavenging activity, lipid peroxidation (LPO) inhibition and betacarotene bleaching assays.

\section{MATERIALS AND METHODS}

\section{Plant Materials, Pre-treatments and Chemicals}

Fresh fronds of Elaeis guineensis were collected from three 10-year old oil palm in Sime Darby East Plantation, Carey Island, Selangor, Malaysia. On the same day, the middle leaflets of all the plant materials were separated from rachis and subjected to pretreatments prior to extraction. Green and matured leaves were selected, washed and rinsed with distilled water to remove dust and contaminants, then air-dried under shade to evaporate surface moisture. The treated leaves were cut into small pieces and pulverised into coarse powder $(\leq 2 \mathrm{~mm})$. 
The DPPH, sodium phosphate dibasic $\left(\mathrm{Na}_{2} \mathrm{HPO}_{4}\right)$, sodium phosphate monobasic $\left(\mathrm{NaH}_{2} \mathrm{PO}_{4}\right)$, Tween 80, Folin-Ciocalteu reagent and beta-carotene were purchased from Sigma-Aldrich, Co., St. Louis, Mo, USA. Butylated hydroxytoluene (BHT), iron (II) sulphate $\left(\mathrm{FeSO}_{4}\right)$, 2-thiobarbituric acid (TBA), trichloroacetic acid (TCA) and HPLCgrade solvents, namely, methanol and $n$-hexane, were purchased from Merck KGaA, Darmstadt, Germany. Sodium sulphate $\left(\mathrm{Na}_{2} \mathrm{SO}_{4}\right)$ anhydrous, and reagent grade methanol, $n$-hexane and ethyl acetate used for extraction and partitioning were purchased from Systerm, Malaysia.

\section{Extraction}

The pulverised oil palm leaves were subjected to ultrasonic-assisted extraction $(16 \mathrm{kHz}, 30 \mathrm{~min})$ using Ultrasonic bath (WiseClean, DAIHAN Scientific Co., Ltd, South Korea) with methanol $(11 \times 1,500 \mathrm{ml} \times 3)$ (Luque de Castro and da Silva, 1997). The methanolic extract was collected and combined while trace of water was removed using anhydrous sodium sulphate, filtered and the filtrate was evaporated under reduced pressure using a rotary evaporator at $40^{\circ} \mathrm{C}$ to a dark green and sticky crude methanolic extract $(\mathrm{MeOH}, 10.9 \%)$.

\section{Partition of Crude Methanolic Extract}

The crude methanolic extract was then extracted and concentrated in vacuo to obtain a brownish green hexane fraction (HEX, 22.1\%). The hexane insoluble residue was further partitioned using ethyl acetate and water (ratio 1:1) to give a dark greenish brown ethyl acetate fraction (EA, 14.2\%) and a brown sticky water fraction (WATER, 58.94\%) after evaporated to dryness under vacuum. The blackish brown insoluble solid remained after partitioning was collected as insoluble fraction (INSOL, 2.20\%).

\section{Antioxidant Activity Assays}

DPPH radical-scavenging activity assay. Samples were dissolved in methanol and diluted to various concentrations. DPPH radical-scavenging activity of various extracts was determined using spectrometric method as described (Brand-Williams et al., 1995) with some modifications on volumes in proportion. The 96-well microplate was used for this assay. BHT was used as standard reference. The $50 \mu \mathrm{l}$ of sample solution was mixed with $50 \mu \mathrm{l}$ of $200 \mu \mathrm{M}$ DPPH solution in methanol. A control was prepared by mixing $50 \mu \mathrm{l}$ of methanol and $50 \mu \mathrm{l}$ of $200 \mu \mathrm{M}$ DPPH solution in methanol. The DPPH free radical was prepared freshly before analysis and protected from light throughout analysis. Absorbance was measured during analysis to confirm the stability of the free radical. The mixture was incubated for 30 min at room temperature in dark. The absorbance was measured in microplate-reader at $517 \mathrm{~nm}$, by using OASYS UVM 340, Austria.

DPPH radical-scavenging activity $(\%)=\left[\left(A_{C}-A_{S}\right) /\right.$ $\left.A_{\mathrm{C}}\right] \times 100$

where $A_{C}$ is the absorbance of the control at $t=30 \mathrm{~min}$ and $A_{S}$ is the absorbance of the sample at $t=30 \mathrm{~min}$.

\section{LPO Inhibition Assay}

Thiobarbituric acid reactive species (TBARS) assay was used to measure the lipid peroxide formed using egg yolk homogenates as lipid-rich media, as described (Ruberto and Baratta, 2000). The samples were dissolved in methanol and diluted to various concentrations. Egg homogenates were prepared by adding $1.25 \mathrm{~g}$ egg yolk in $100 \mathrm{ml}$ phosphate buffer in water, which consists of $1.52 \mathrm{~g}$ $\mathrm{Na}_{2} \mathrm{HPO}_{4}, 0.58 \mathrm{~g} \mathrm{NaH}_{2} \mathrm{PO}_{4}, 0.85 \mathrm{~g} \mathrm{NaCl}$ and 1 litre distilled water. The phosphate buffer was adjusted to $\mathrm{pH} 7.4$ prior to addition of egg yolk. The $0.1 \mathrm{ml}$ of sample solution was added to $1 \mathrm{ml}$ buffered egg yolk in glass centrifuge tube, and then $0.2 \mathrm{ml}$ $3 \mathrm{mM} \mathrm{FeSO}_{4}$ solution was added to induce lipid peroxidation. A control was prepared by replacing the $0.1 \mathrm{ml}$ of sample solution with $0.1 \mathrm{ml}$ methanol. The reaction mixture was kept in dark for $1 \mathrm{hr}$ at room temperature. After incubation, $0.5 \mathrm{ml}$ of $15 \%$ TCA aqueous solution was added immediately to terminate LPO and prevent any further reaction. Then, $1 \mathrm{ml}$ of $1 \%$ TBA aqueous solution was added to form pinkish complex as malondialdehyde was formed. The mixture was stirred with a vortex mixer, and incubated in water bath at $95^{\circ} \mathrm{C}$ for 10 min to ensure completion of reaction. After cooling to room temperature, the mixture was centrifuged at $3500 \mathrm{rpm}$ for $10 \mathrm{~min}$. The $200 \mu \mathrm{l}$ of the supernatant was transferred into a 96-well plate and absorbance at $532 \mathrm{~nm}$ was measured.

LPO inhibition activity $(\%)=\left[\left(A_{C}-A_{S}\right) / A_{C}\right] \times 100$

where $A_{C}$ is the absorbance of the control at $t=1 \mathrm{hr}$ and $A_{S}$ is the absorbance of the sample at $t=1 \mathrm{hr}$

\section{Beta-carotene Bleaching Assay}

The coupled oxidation of beta-carotene and linoleic acid was determined using the method described (Chew et al., 2008). An emulsion was prepared by adding $0.02 \mathrm{ml}$ linoleic acid and 0.2 $\mathrm{ml}$ Tween 80 to the $1 \mathrm{ml}$ beta-carotene solution in chloroform $\left(100 \mu \mathrm{g} \mathrm{ml}^{-1}\right)$. The chloroform was then evaporated and oxygen-saturated ultrapure water was added to the residue. The samples were dissolved in methanol. The beta-carotene/linoleic acid emulsion was shaken vigorously and $200 \mu \mathrm{l}$ of this emulsion were added to $8 \mu \mathrm{l}$ sample solutions of various concentrations in 96-well plate. A control was prepared using $8 \mu \mathrm{l}$ methanol instead of $8 \mu \mathrm{l}$ 
of sample solution. The absorbance was read at 470 $\mathrm{nm}$ immediately after the emulsion was prepared $(t=0 \mathrm{~min})$, the mixture was incubated at $50^{\circ} \mathrm{C}$ and absorbance was measured every $20 \mathrm{~min}$ interval for $2 \mathrm{hr}$.

beta-carotene bleaching inhibition activity $(\%)$

$=\left[\left(A_{S(120)-A C(120)}\right) /\left(A_{C(0)-A C(120)}\right)\right] \times 100$

where $\mathrm{A}_{\mathrm{S}(120)}$ is the absorbance of the sample at $t=2 \mathrm{hr}$,

$A_{C(120)}$ is the absorbance of the control at $t=2 \mathrm{hr}$ and

$A_{\mathrm{C}(0)}$ is the absorbance of the control at $t=0 \mathrm{~min}$

\section{Determination of TPC}

TPC in fractions was determined by the FolinCiocalteu procedure (Kähkönen et al., 1999). All the fractions and BHT were dissolved in 50\% methanol and prepared in various concentrations. In each well of a 96-well microplate, the sample $(10 \mu \mathrm{l}$, in triplicate) was mixed with $150 \mu \mathrm{l}$ of water and $30 \mu \mathrm{l}$ of Folin-Ciocalteu reagent. After $6 \mathrm{~min}$, and $75 \mu \mathrm{l}$ of $7 \%(\mathrm{w} / \mathrm{v})$ sodium carbonate was added. The mixture was kept in the dark for $2 \mathrm{hr}$ before measuring the absorbance at $765 \mathrm{~nm}$ in microplate-reader, using TECAN Infinite ${ }^{\circledR}$ M200, Switzerland. A calibration curve was constructed using gallic acid and results were expressed as $\mathrm{mg}$ gallic acid equivalents ( $\mathrm{mg}$ GAE g-1).

\section{Statistical Analysis}

The tests were performed in triplicate for each independent sample to be analysed. All data were expressed as mean \pm standard deviation in Table 1. Correlation between the TPC and the antioxidant activities was determined using Pearson Product Moment Correlation and Spearman Rank Order tests. The results were tabulated in Tables 2 and 3. P $<0.050$ was considered statistically significant.

\section{RESULTS AND DISCUSSION}

Various techniques are employed to evaluate antioxidant activity of single compounds or complex mixtures such as natural product extracts; however different techniques exhibit antioxidant activity through different mechanisms and pathways. Thus, a single procedure may not be able to represent all possible mechanisms characterising an antioxidant sufficiently. The use of different methods is crucial in assessing antioxidant activity to investigate the potential antioxidant capacities via different mechanisms. Therefore in this study, three assays, namely, scavenging activity on DPPH radicals, inhibition of lipid peroxidation induced by $\mathrm{Fe}^{2+}$ and beta-carotene bleaching in an emulsion of linoleic acid were conducted to evaluate in vitro antioxidant properties of the fractions.

\section{DPPH Radical-scavenging Activity Assay}

DPPH in its radical form has a deep violet colour with a strong absorbance at $517 \mathrm{~nm}$. In the presence of antioxidant compounds, electron or hydrogen atom will transfer from the antioxidant to DPPH radical and a pale brownish yellow solution is formed. The change of absorbance values at $517 \mathrm{~nm}$ is proportional to the reduction level of DPPH radicals. In this assay, the methanolic DPPH solutions were incubated with palm leaf fraction at different concentrations to determine its antioxidant activity. Figure 1a shows the DPPH radical-scavenging ability decreased in the order INSOL $>$ BHT $>\mathrm{MeOH}>$ EA $>$ WATER $>$ HEX. The INSOL fraction was the most potent radical scavenger among these fractions and showed stronger radical-scavenging ability than the positive control BHT. DPPH assay is usually categorised as electron transfer reaction; the free radical in fact

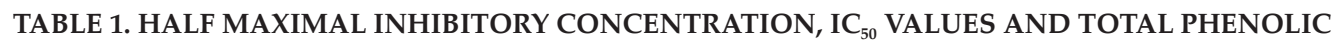
CONTENTS OF THE FRACTIONS AND BHT*

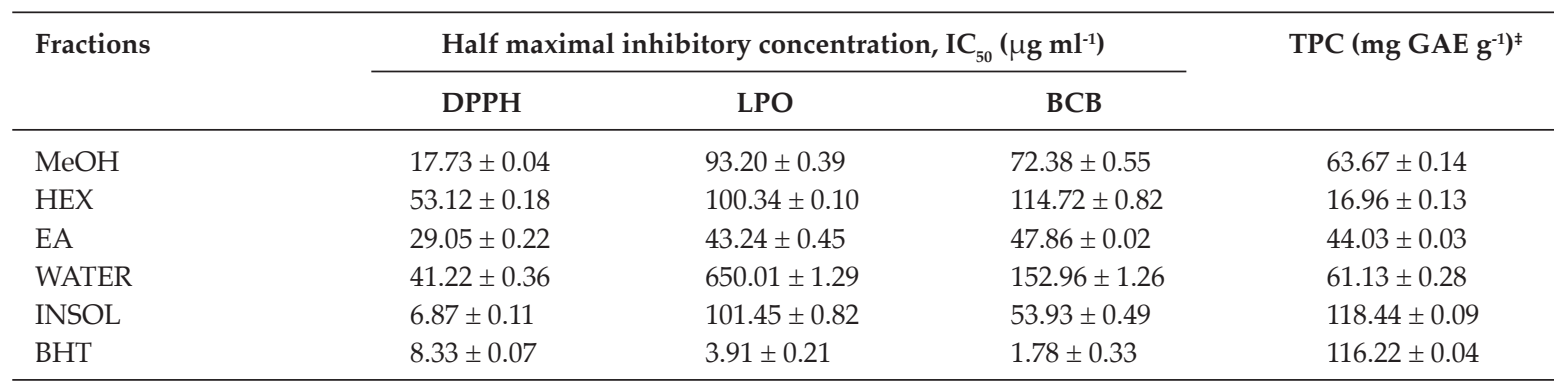

Note: *Results are means of three independent samples analysed in triplicate \pm standard deviation.

${ }^{\ddagger}$ Results are expressed as $\mathrm{mg}$ of gallic acid equivalents $/ \mathrm{g}$ sample.

BHT - butylated hydroxytoluene.

DPPH - 2-2-diphenyl-1-picrylhyderazy.

BCB - benzocyclobutene.

LPO - lipid peroxidation.

TPC - total phenolic contents. 
TABLE 2. CORRELATION COEFFICIENTS AND P VALUES FOR BIOASSAYS AND TPC BASED ON PEARSON PRODUCT MOMENT CORRELATION

\begin{tabular}{|c|c|c|c|c|}
\hline \multicolumn{2}{|c|}{ Pairs of variables tested } & \multicolumn{2}{|c|}{$\mathrm{IC}_{50}\left(\mu \mathrm{g} \mathrm{ml}^{-1}\right)$} & \multirow[t]{2}{*}{ TPC (mg GAE $\left.\mathrm{g}^{-1}\right)$} \\
\hline & & LPO & ВСВ & \\
\hline \multirow{6}{*}{$\begin{array}{l}\widetilde{I} \\
\underset{\Xi}{E} \\
\underbrace{\infty} \\
\underbrace{\infty}\end{array}$} & DPPH & $0.444^{*}$ & $0.789^{*}$ & $-0.896^{*}$ \\
\hline & & $0.378^{\ddagger}$ & $0.0624^{\ddagger}$ & $0.0158^{\ddagger}$ \\
\hline & LPO & - & $0.809^{*}$ & $-0.161^{*}$ \\
\hline & & & $0.0511^{\ddagger}$ & $0.761^{\ddagger}$ \\
\hline & $\mathrm{BCB}$ & - & - & $-0.605^{*}$ \\
\hline & & & & $0.203^{\ddagger}$ \\
\hline
\end{tabular}

Note: *Correlation coefficient.

${ }^{\ddagger} \mathrm{P}$ value.

LPO - lipid peroxidation.

$\mathrm{BCB}$ - beta-carotene bleaching.

TPC - total phenolic contents.

GAE - gallic acid equivalents.

DPPH - 2,2-diphenyl-1-picrylhydrazy.

TABLE 3. CORRELATION COEFFICIENTS AND P VALUES FOR BIOASSAYS AND TPC BASED ON SPEARMAN RANK ORDER CORRELATION

\begin{tabular}{|c|c|c|c|c|}
\hline \multirow{2}{*}{\multicolumn{2}{|c|}{ Pairs of variables tested }} & \multicolumn{2}{|c|}{$\mathrm{IC}_{50}\left(\mu \mathrm{g} \mathrm{ml}^{-1}\right)$} & \multirow[t]{2}{*}{ TPC (mg GAE $\mathrm{g}^{-1}$ ) } \\
\hline & & LPO & BCB & \\
\hline \multirow{6}{*}{ 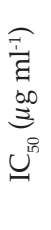 } & DPPH & $0.257^{*}$ & $0.657^{*}$ & $-0.943^{*}$ \\
\hline & & $0.658^{\ddagger}$ & $0.175^{\ddagger}$ & $0.0167^{\ddagger}$ \\
\hline & LPO & - & $0.829^{*}$ & $-0.0286^{*}$ \\
\hline & & & $0.0583^{\ddagger}$ & $0.000^{\ddagger}$ \\
\hline & BCB & - & - & $-0.429^{*}$ \\
\hline & & & & $0.419^{\ddagger}$ \\
\hline
\end{tabular}

Note: *Correlation coefficient.

LPO - lipid peroxidation.

${ }^{\ddagger} \mathrm{P}$ value.

DPPH - 2,2-diphenyl-1-picrylhydrazy.

$\mathrm{BCB}$ - beta-carotene bleaching.

TPC - total phenolic contents.

GAE - galin acid equivalents.

may be reduced either by electron transfer or by $\mathrm{H}$ atom transfer. Our present findings as presented in Figure $1 a$ conclude that oil palm leaf $\mathrm{MeOH}$ and its fractions possess comparable radical-scavenging power with that of synthetic antioxidant BHT.

\section{LPO Inhibition Assay}

This method is an in vitro LPO induced by $\mathrm{Fe}^{2+}$ from $\mathrm{FeSO}_{4}$ aqueous solution. Transition metal ions $\mathrm{Fe}^{2+}$ provoked LPO by reductive cleavage of endogenous lipid peroxides (ROOH) of phospholipids in plasma membrane (Repetto et al., 2010; Repetto and Boveris, 2012). ROOH are unstable and decompose to form various compounds, which include MDA, a reactive carbonyl compound, naturally occurring product of LPO. It is frequently used as an indicator of oxidative stress at cellular level. In our study, MDA produced from $\mathrm{Fe}^{2+}$ -induced oxidation of polyunsaturated fatty acids in egg homogenates, reacted with two molecules of TBA to yield a pinkish red complex with strong absorption at $532 \mathrm{~nm}$. This method measures the intensity of pink chromophore generated in reaction of TBA with MDA. In the presence of antioxidant compounds, rate of polyunsaturated fatty acids oxidation can be diminished, and hence less MDA being produced, generating less pinkish red complex, gave rise to low absorbance at 532 $\mathrm{nm}$. The absorbance values at $532 \mathrm{~nm}$ provide a measure of the extent of LPO. As shown in Figure $1 b$, the ethyl acetate (EA), MeOH, HEX and WATER fractions have similar inhibitory power. The LPO inhibition decreased in order $\mathrm{BHT}>\mathrm{EA}>\mathrm{MeOH}$ $>$ HEX $>$ INSOL $>$ WATER. This result indicates that the polar water fraction has the lowest LPO inhibition among all the fractions and BHT tested. We believe this is due to compounds extracted using water have low solubility in the egg homogenates system, creating a hindrance to intimate contact between polar antioxidant compounds and less polar polyunsaturated fatty acids. 


\section{Beta-carotene Bleaching Assay}

In this assay, an emulsion of linoleic acid was oxidised by oxygen-saturated ultrapure water to form radicals. The radicals produced upon the abstraction of a hydrogen atom from one of its methylene groups attacked the beta-carotene molecules, which lost the double bonds, hence its characteristic orange colour at $470 \mathrm{~nm}$. Presence of antioxidants can slow down the rate of beta-carotene bleaching. The antioxidant activity was expressed as percent inhibition relative to the control. It can be observed from Figure $1 c$ that the beta-carotene antioxidant activity increased with increasing concentration of the samples used. The control without addition of antioxidant decolourised at highest rate and decreasing rate were observed in the presence of WATER $>\mathrm{HEX}>\mathrm{MeOH}>\mathrm{EA}$ $>$ INSOL $>$ BHT. Similar to LPO inhibition assay, this result shows that the polar water fraction has the lowest activity among all the fractions and BHT tested. Linoleic acid used is polyunsaturated

(a)
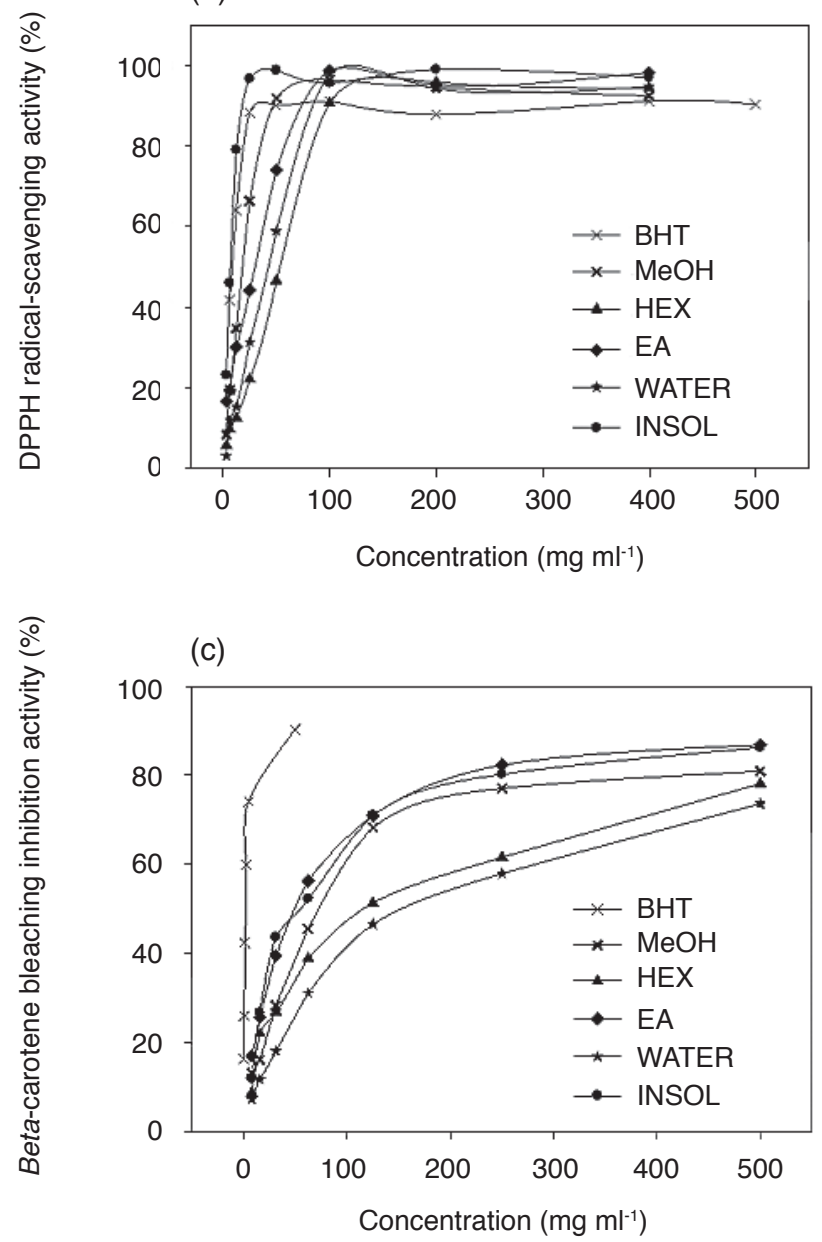

omega-6 fatty acid, which is also susceptible for LPO. Water-soluble polar antioxidant compounds in water fraction are of lower efficiency in protecting beta-carotene of low polarity as compared to antioxidant compounds in other fractions.

\section{Total Phenolic Contents (TPC)}

Naturally occurring phenolic compounds are secondary metabolites in the plants and have received great attention as potential natural antioxidants in terms of their abilities to act as radical scavengers, reducing agents, hydrogen donors, singlet oxygen quenchers, hydroxyl radical quenchers and metal chelators. They are synthesised by plants to resist external stress. It has been disclosed that light induces the synthesis of flavonoids (Dixon and Paiva, 1995) and they are strongly believed to protect plants against UV-B damage and cell destruction by preventing DNA from dimerisation and breakage (Strack, 1997). Being

(b)

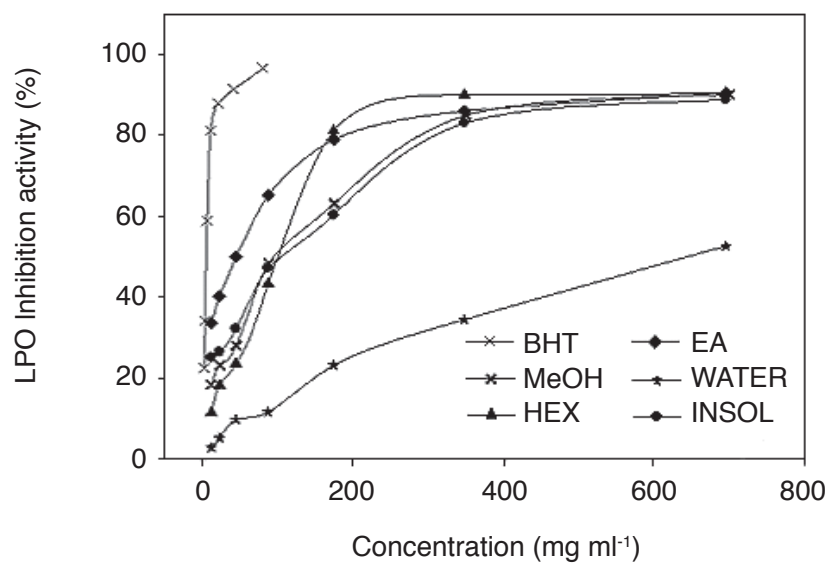

(d)

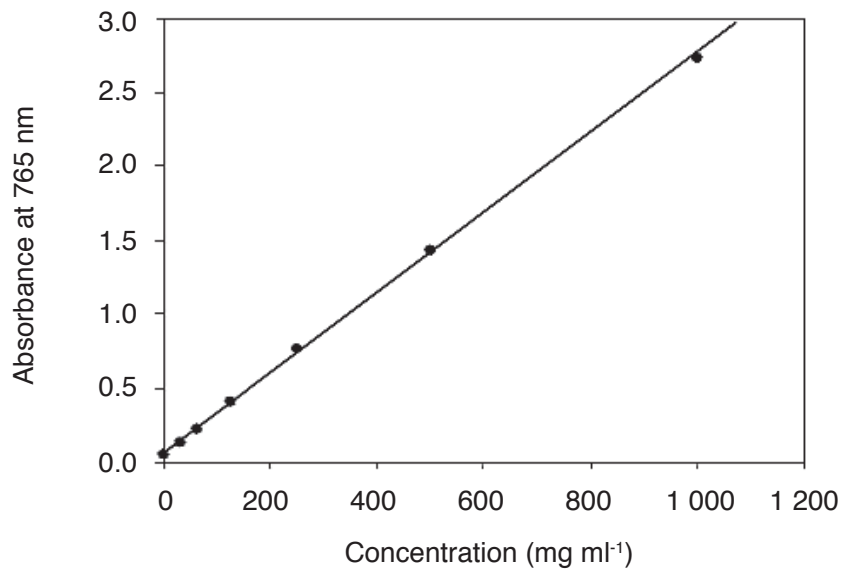

Figure 1. (a) Scavenging effect of various extracts at a range of concentrations on the 2,2-diphenyl-1-picrylhydrazyl radical (DPPH•) and butylated hydroxytoluene (BHT). (b) Inhibition of $\mathrm{Fe}^{2+}$-induced lipid peroxidation by various extracts at a range of concentrations compared to standard reference BHT. (c) Inhibition of $\beta$-carotene bleaching by various extracts at a range of concentrations and BHT. (d) Calibration curve of gallic acid to determine Total Phenolic Content in the extracts $\left(R^{2}=0.9996\right)$. 
a maritime country close to the equator, Malaysia naturally has abundant sunshine and thus solar radiation. On the average, Malaysia receives about $6 \mathrm{hr}$ of sunshine per day. To ensure survival, plants have developed mechanisms to produce efficient and sufficient antioxidants to prevent degradation of biomolecules such as pigments, DNA, lipids, proteins and carbohydrates. With these mechanisms, oil palm also able to protect its fruits and oil from oxidative stress. This partially explains why oil palm frond have generally increased accumulation of antioxidants and phenolic compounds as tabulated in Table 1.

Figures $1 a, 1 b$ and $1 c$ suggest that the antioxidant of all the fractions and standard reference BHT was dose-dependent in DPPH, LPO inhibition and betacarotene bleaching assays. In our study, we find that the DPPH assay is the fastest and least tedious way to evaluate radical-scavenging ability and estimate antioxidant activity. In the present study, all samples and DPPH were completely miscible in methanol. We suggest that this assay is the most suitable and representative for evaluating the antioxidant activity of our extract, fractions and BHT. It also showed high reproducibility which is in agreement with an earlier report (Thaipong et al., 2006).

\section{Correlation between TPC and Antioxidant Activities}

Statistical analyses on the correlation between TPC and antioxidant activities showed good negative correlation between TPC with DPPH based on both Pearson Product Moment Correlation and Spearman Rank Order Correlation. These data suggest that phenolic compounds in oil palm frond are powerful radical scavengers. Similar trend was observed in previous studies (Kumar et al., 2008). Analysis on the TPC with LPO inhibitory activity and TPC with beta-carotene bleaching inhibitory activity had very poor correlations, implying that different mechanisms of antioxidant actions in oil palm frond fractions. The difference in the correlations between TPC and antioxidant assays suggests there are different groups of phenolic compounds corresponding to different assays for the determination of the antioxidant properties, this concurs with previous studies (Khledkhoudja et al., 2014; Prior et al., 2005; Stagos et al., 2012).

\section{CONCLUSION}

The $\mathrm{IC}_{50}$ values and TPC of $\mathrm{MeOH}$ extract and BHT as shown in Table 1 suggested that $\mathrm{MeOH}$ extract obtained from OPF could be a natural substitute of BHT as antioxidant. It exhibited half of the strength of BHT in radical scavenging ability and TPC. Converting this strength into economical figure,
$\mathrm{MeOH}$ extract from OPF may generate up to USD 13 per $100 \mathrm{~g}$ as BHT costs about USD 26 per 100 g. This implies that oil palm frond production of 45 million tonnes in 2014 may generate 4.9 million tonnes of $\mathrm{MeOH}$ extract which is equivalent to 637 billion USD. However, there are also other factors in determining the feasibility of palm leaves as source for antioxidants.

\section{REFERENCES}

ABEYWARDENA, M; RUNNIE, I; NIZAR, $\mathrm{M}$ and HEAD, R (2002). Polyphenol-enriched extract of oil palm fronds (Elaeis guineensis) promotes vascular relaxation via endothelium-dependent mechanisms. Asia Pacific J. Clinical Nutrition, 11(S7): 467-472.

BALASUNDRAM, N; BUBB, W; SUNDRAM, K and SAMMAN, S (2003). Antioxidants from palm (Elaeis guineensis) fruit extracts. Asia Pacific J. Clinical Nutrition, 12(Suppl): 37.

BRAND-WILLIAMS, W; CUVELIER, $\mathrm{M}$ E and BERSET, C (1995). Use of free radical method to evaluate antioxidant activity. Lebensmittel Wissenschaft \& Technologie, 28: 25-30.

BRANEN, A L (1975). Toxicology and biochemistry of butylated hydroxyl anisole and butylated hydroxyl toluene. J. Amer. Oil Chem. Soc., 52: 59-63.

CHEW, Y L; LIM, Y Y; OMAR, M and KHOO, K S (2008). Antioxidant activity of three edible seaweeds from two areas in South East Asia. Food Chemistry, 41: 1067-1072.

DAS, N P and PEREIRA, T A (1990). Effects of flavonoids on thermal autoxidation of palm oil: structure-activity relationship. J. Agricultural and Food Chemistry, 44: 497-501.

DIXON, R A and PAIVA, N L (1995). Stress-induced phenylpropanoid metabolism. Plant Cell, 7: 10851097.

FOTI, M; PIATTELLI, M; BARATTA, $\mathrm{M} \mathrm{T}$ and RUBERTO, G (1996). Flavonoids, coumarins and cinnamic acids as antioxidants in micellar system. J. Agricultural and Food Chemistry, 44: 497-501.

IBRAHIM, Z; AZIZ, A A; RAMLI, R; MOKHTAR, A; OMAR, R and LEE, S (2014). Production of medium density fibreboard (MDF) from oil palm trunk (OPT). J. Applied Sciences, 14(11): 1174-1179.

JAFFRI, J M; MOHAMED, S; AHMAD, I N; MUSTAPHA, N M; MANAP, Y A and ROHIMI, N (2011). Effects of catechin-rich oil palm leaf extract 
on normal and hypertensive rats' kidney and liver. Food Chemistry, 128(2): 433-441.

KÄHKÖNEN, M P; HOPIA, A I; VUORELA, H J; RAUHA, J P; PIHLAJA, K; KULAJA, T S and HEIHONEN, M (1999). Antioxidant activity of plant extracts containing phenolic compounds. $J$. Agricultural and Food Chemistry, 47: 3954-3962.

KHLEDKHOUDJA, N; BOULEKBACHEMAKHLOUF, L and MADANI, K (2014). Antioxidant capacity of crude extracts and their solvent fractions of selected Algerian Lamiaceae. Industrial Crops and Products, 52: 177-182.

KINNOUDO, C (2007). Antimalarial properties of extracts of Elaeis guineensis (oil palm) leaves. PCT International Application, WO2007129136(A1).

KUMAR, K S; GANESAN, K and RAO, P V S (2008). Antioxidant potential of solvent extracts of Kappaphycus alvarezii (Doty) - an edible seaweed. Food Chemistry, 107: 289-295.

LAU, H L N; CHOO, Y M; MA, A N and CHUAH, $\mathrm{C} \mathrm{H}$ (2007). Extraction and identification of watersoluble compounds in palm-pressed fiber by SC$\mathrm{CO}_{2}$ and GC-MS. American J. Environmental Sciences, 3: 54-59.

LUQUE DE CASTRO, M D and DA SILVA, M P (1997). Strategies for solid sample treatment Trends in Analytical Chemistry, 16: 16-24.

MACLELLAN, M (1983). Palm oil. J. Amer. Oil Chem. Soc., 60(2): 320-325.

MPOB (2017a). http://bepi.mpob.gov.my/index. $\mathrm{php} / \mathrm{en} /$ statistics / production/168-production2016/746-production-of-crude-oil-palm-2016.html, accessed on 16 March 2017.

MPOB (2017b). http://bepi.mpob.gov.my/index. $\mathrm{php} /$ en/statistics / export/171-export-2016/763monthly-export-of-oil-palm-products-2016.html, accessed on 16 March 2017.

MOHAMED, S (2014). Oil palm leaf: a new functional food ingredient for health and disease prevention. J. Food Processing \& Technology, 05(02).

MOHAMED, S; JAFFRI, J M; MUSTAPHA, N M; AHMAD, I N and MYRSYIDA, A R (2009). Extract from palm leaves and a method for producing the same. PCT International Application, WO2009008697(A1).

NEO, Y; ARIFFIN, A; TAN, C and TAN, Y (2010). Phenolic acid analysis and antioxidant activity assessment of oil palm (E. guineensis) fruit extracts. Food Chemistry, 122(1): 353-359.

NG, M H and CHOO, Y M (2010). Determination of antioxidants in oil palm leaves (Elaeis guineensis). American J. Applied Sciences, 7: 1243-1247.

PHANG, N L; ABDUL, K M F Y; LIM, C K; HAMBALI, S A; SHARIFF, $S$ and THURAISNGAM, $S$ (2009). Extract from oil palm leaves comprising phenolic acids. PCT International Application, WO2009110782(A1).

PRIOR, R L; WU, X and SCHAICH, K (2005). Standardized methods for the determination of antioxidant capacity and phenolics in foods and dietary supplements. J. Agricultural and Food Chemistry, 53: 4290-4302.

REPETTO, M G and BOVERIS, A (2012). Transition metals: bioinorganic and redox reactions in biological systems. Transition Metals: Uses and Characteristics. Nova Science Publishers Inc., New York. p. 349-370.

REPETTO, M G; FERRAROTTI, N F and BOVERIS, A (2010). The involvement of transition metal ions on iron-dependent lipid peroxidation. Archieves of Toxicology, 84: 255-262.

RUBERTO, G and BARATTA, M T (2000). Antioxidant activity of selected essential oil components in two lipid model systems. Food Chemistry, 69: 167-174.

SANTANA-MÉRIDAS, O; POLISSIOU, M; IZQUIERDO-MELERO, $\mathrm{M}$ E; ASTRAKA, K; TARANTILIS, $\mathrm{P}$ A; HERRAIZ-PEÑALVER, $\mathrm{D}$ and SÁNCHEZ-VIOQUE, R (2014). Polyphenol composition, antioxidant and bioplaguicide activities of the solid residue from hydrodistillation of Rosmarinus officinalis L. Industrial Crops and Products, 59: 125-134.

STAGOS, D; PORTESIS, N; SPANOU, C; MOSSIALOS, D; ALIGIANNIS, N; CHAITA, E; PANAGOULIS, C; RERI, E; SKALTSOUNIS, L; TSATSAKIS, A M and KOURETAS, D (2012). Correlation of total polyphenolic content with antioxidant and antibacterial activity of 24 extracts from Greek domestic Lamiaceae species. Food and Chemical Toxicology, 50: 4115-4124.

STRACK, D (1997). Phenolic metabolism. Plant Biochemistry (Dev, P M and Harborne, J B eds.). Academic Press, London. p. 387-416.

SUN, R; SUN, X and ZHANG, S (2001). Quantitative determination of hydroxycinnamic acids in wheat, rice, rye, and barley straws, maize stems, oil palm frond fiber, and fast-growing poplar wood. J. Agricultural and Food Chemistry, 49 (11): 5122-5129. 
TAN, Y A; SUNDRAM, $\mathrm{K}$ and SAMBANTHAMURTHI, R (2001). Water-soluble phenolics from the palm oil industry. Special Publication - Royal Society of Chemistry, 269: 548-551.

THAIPONG, K; BOONPRAKOB, U; CROSBY, K; CISNEROS-ZEVALOOS, L and BRYNE, D H (2006). Comparison of ABTS, DPPH, FRAP, and ORAC assays for estimating antioxidant activity from guava fruit extracts. J. Food Composition and Analysis, 19: 669-675.

TOMAS-BARBERAN, F A; FERRERES, F and GIL, M I (2000). Antioxidant phenolic metabolites from fruit and vegetables and changes during postharvest storage and processing. Bioactive Natural Products (Part D) (Rahman, A ed.). Elsevier Science B. V., Amsterdam. p. 739-795. 